\title{
Effects of a flexible galantamine dose in Alzheimer's disease: a randomised, controlled trial
}

\author{
K Rockwood, J Mintzer, L Truyen, T Wessel, D Wilkinson
}

Centre for Health Care of the Elderly, QEII Health Sciences Centre, 1421-5955 Veterans' Memorial Lane, Halifax, Canada B3H 2E1

K Rockwood

Department of Psychiatry, Medical University of South Carolina, Charleston, SC, USA

J Mintzer

Janssen Research Foundation, Beerse, Belgium

L Truyen

Janssen Research Foundation, Titusville, NJ, USA

$\mathrm{T}$ Wessel

On behalf of the Galantamine International-2 Study

Group, ^ Thornhill Research Unit, Moorgreen Hospital, Southampton, UK D Wilkinson

${ }^{\star}$ Members listed at end of paper

Correspondence to: Professor K Rockwood rockwood@is.dal.ca

Received 7 December 2000 and in revised form

9 May 2001

Accepted 17 May 2001

\begin{abstract}
Objective-To assess the efficacy and safety of galantamine in Alzheimer's disease at 3 months using flexible dose escalation.
\end{abstract}

Methods-A randomised, double blind, placebo controlled trial in 43 centres in the United States, Canada, Great Britain, South Africa, Australia, and New Zealand. Patients with probable Alzheimer's disease $(n=386 ; 171$ women) with a score of 11-24 on the mini mental state examination, and a score $\geqslant 12$ on the cognitive subscale of the Alzheimer's disease assessment scale (ADAS-cog) were randomised to placebo, or galantamine escalated over 4 weeks to a maintenance dose of 24 or $32 \mathrm{mg} /$ day. The primary outcome measures were the change in ADAS-cog score and the clinician's interview based impression of change plus caregiver input (CIBIC-plus) score. Activities of daily living (ADL) and behavioural symptoms were secondary outcomes. To compare the effects of highest levels of dosing, an observed cases (OC) analysis was undertaken, with classic intention to treat (ITT) and ITT with last observation carried forward (LOCF) as confirmatory analyses.

Results-At 3 months, galantamine (24-32 mg/day) produced a significantly better outcome on cognitive function than placebo (treatment difference $=1.9$ points on ADAS-cog, $p=0.002$ ) and a significantly better global response than placebo, as measured by CIBIC-plus (deterioration in $21 \%$ of patients on galantamine $v 37 \%$ on placebo; $p<0.001)$. Galantamine produced significant benefits on basic and instrumental ADL. Behavioural symptoms did not change significantly from baseline levels in either group. Adverse events (primarily gastrointestinal) were of mild to moderate intensity. There were no important differences between the $O C$, ITT, and ITT/LOCF analyses. Most patients $(82 \%)$ who were maintained on the higher dose of galantamine completed the study.

Conclusions-Patients on galantamine, compared with those on placebo, experienced benefits in cognitive function and instrumental and basic activities of daily living. Flexible dose escalation of galantamine was well tolerated.

(F Neurol Neurosurg Psychiatry 2001;71:589-595)

Keywords: Alzheimer's disease; galantamine; nicotinic receptors; acetylcholinesterase inhibition; activities of daily living
The enhancement of cholinergic function remains the most successful approach to date for ameliorating the symptoms of Alzheimer's disease. This strategy is based on the cholinergic hypothesis', ${ }^{2}$ which proposes that degeneration of cholinergic neurons in the basal forebrain and the associated loss of cholinergic neurotransmission in the cerebral cortex contribute significantly to the cognitive decline seen in patients with Alzheimer's disease. Acetylcholinesterase inhibition is currently the most established strategy for correcting cholinergic deficits in Alzheimer's disease and improving cognitive symptoms. ${ }^{3}{ }^{4}$ The development of newer cholinesterase inhibitors seems to have overcome the initial problem of hepatotoxicity, seen with tacrine and velnacrine..$^{5-7}$ Nevertheless, gastrointestinal symptoms, and other side effects, such as insomnia, sometimes reported with donepezil, ${ }^{8}{ }^{9}$ and muscle weakness, reported with metrifonate, ${ }^{10}$ can be potentially troublesome side effects.

As the disease progresses, cognitive decline is accompanied by functional impairment, which increases patients' dependence on caregivers and influences the decision to admit patients to long term care facilities. ${ }^{112}$ The precise benefits of cholinesterase inhibitors are still an issue of debate, with some commentators unconvinced that the reported improvements in cognition translate into clinically important effects on a patient's functional ability. ${ }^{13} 14$

Galantamine is a novel agent that modulates nicotinic receptors ${ }^{15} 16$ and potentiates nicotinic neurotransmission in addition to inhibiting acetylcholinesterase. ${ }^{17}{ }^{18}$ Given the loss of nicotinic receptors that accompanies the impairment of presynaptic cholinergic function in Alzheimer's disease, ${ }^{19}{ }^{20}$ and their role in memory and learning ${ }^{1121}$ maintaining nicotinic activity may have therapeutic value. ${ }^{15}$ Galantamine binds to an allosteric binding site on nicotinic receptors, thereby potentiating the response of these receptors to the natural agonist, acetylcholine. ${ }^{15}$ This enhancement of nicotinic neurotransmission may be clinically relevant because activation of presynaptic nicotinic receptors has been shown to increase the release of acetylcholine and glutamate, which are deficient in Alzheimer's disease and are thought to be involved in memory and learning. ${ }^{21}{ }^{22}$ The beneficial effects of galantamine in patients with Alzheimer's disease have already been demonstrated in two large 6 month placebo controlled trials that used a 4 week dose escalation period to achieve fixed maintenance doses of 24 or $32 \mathrm{mg} /$ day. ${ }^{23}{ }^{24}$ As 
more information becomes available on specific patterns of treatment effects with galantamine (perhaps, for example, early stabilisation of activities of daily living (ADL), lack of sleep disturbance, or improved attention) it may be that the clinical role of the nicotinic receptor might be better understood. As the tolerability of cholinesterase inhibitors is dose related, ${ }^{2}$ the present study was undertaken to test the efficacy and safety of galantamine using a flexible dose, in patients with mild to moderate Alzheimer's disease, over 3 months.

\section{Methods}

PATIENTS

Patients with a history of cognitive decline that had been gradual in onset and progressive for at least 6 months were included. Other inclusion criteria were:

- A diagnosis of probable Alzheimer's disease according to the criteria of the National Institute of Neurological and Communicative Disorders and Stroke and Alzheimer's Disease and Related Disorders Association (NINCDS/ ADRDA) ${ }^{24}$

- Presence of mild to moderate dementia (a score of 11-24 on the mini mental state examination (MMSE) $)^{25}$ and a score $\geqslant 2$ on the standard cognitive subscale of the Alzheimer's disease assessment scale (ADAS-cog) ${ }^{26}$

Patients also had to have regular contact with a responsible caregiver. Those with concomitant diseases such as hypertension, congestive heart failure, non-insulin dependent diabetes mellitus, and hypothyroidism were included in the study provided the disease was controlled. Patients were excluded from the study if they had evidence of other neurodegenerative disorders; any cardiovascular disease thought likely to prevent completion of the study; clinically significant cerebrovascular, hepatic, renal, pulmonary, metabolic or endocrine conditions; clinically significant psychiatric disease, including moderate or severe or uncontrolled behavioural disturbances; urinary outflow obstruction; an active peptic ulcer; any history of epilepsy, or significant drug or alcohol misuse.

Patients previously treated with any cholinomimetic agent for Alzheimer's disease, except muscarinic agonists, were also excluded. Any other medication being taken to treat dementia had to be discontinued. The use of other concomitant medication was permitted, except that, where possible, drugs with a psychotropic action were discontinued 48 hours before cognitive evaluation. Drugs with anticholinergic effects or cholinomimetic effects were avoided.

The trial was performed in accordance with the Declaration of Helsinki and subsequent revisions and approved by ethics committees at each centre. The patient (or a representative), together with the carer, provided written informed consent to participate.

DESIGN

This was a 3 month, parallel group, placebo controlled trial undertaken in 43 centres in six countries (Australia, Canada, Great Britain, New Zealand, South Africa, and the United States). After a 4 week, single blind, placebo run in phase, patients were randomised to receive galantamine or placebo in a 2:1 ratio using a computer generated code. The assignments were kept in sealed, opaque envelopes until the point of allocation. Patients treated with galantamine received $8 \mathrm{mg} /$ day for 1 week, increasing to $16 \mathrm{mg} /$ day for the 2 nd week and to $24 \mathrm{mg} /$ day (12 mg twice daily) for the $3 \mathrm{rd}$ week. During week 4, the galantamine or placebo dose could be increased (to 32 $\mathrm{mg} /$ day - that is, $16 \mathrm{mg}$ twice daily for galantamine) at the discretion of the investigator, based on tolerance. By the end of the 4 th week the investigator could reduce the dose (for galantamine from $32 \mathrm{mg} /$ day to $24 \mathrm{mg} /$ day). Patients continued with their final dose of galantamine or placebo for a further 2 months. Throughout the study, all individual doses of galantamine and placebo were otherwise identical single tablets taken twice daily.

The primary efficacy variables were the standard, 11 item cognitive subscale of the Alzheimer disease assessment scale (ADAS$\operatorname{cog} / 11)^{26}$ to assess cognitive function, and the clinician's interview based impression of change plus caregiver input (CIBIC-plus) ${ }^{27}$ to assess overall clinical response. The CIBICplus was scored by a trained clinician based on separate interviews with the patient and the caregiver; the clinician was blinded to other assessments. Scores ranged from 1 to 7 (1=markedly improved with respect to baseline, $7=$ markedly worse).

Secondary efficacy variables were:

- The expanded (13 item) version of the standard ADAS-cog subscale (ADAS- $\operatorname{cog} / 13$ ), with a score range of $0-85 .^{28}$

- The proportions of responders (defined as improvements in ADAS-cog/11 $\geqslant 4$ points from baseline)..$^{29}$

- Neuropsychiatric inventory (NPI), which assesses 10 domains of behavioural symptoms (score range of $0-120){ }^{30}$

- Disability assessment for dementia (DAD) scale, based on an interview with the caregiver, to assess basic and instrumental activities of daily living (ADL), initiation, planning and organisation, performance, and leisure; the DAD has a score range $0-100 .^{31}$

All of the efficacy assessments were performed at baseline and after 1 and 3 months.

Safety evaluations throughout the study comprised physical examinations, ECG, vital sign measurements, standard laboratory tests, and monitoring for adverse events (classified according to World Health Organisation preferred terms). For the first 2 weeks, the investigator contacted the patient or caregiver by phone at weekly intervals to record any adverse events. Safety was further evaluated at monthly clinic visits at weeks 3 and 4, and after 2 and 3 months. Sleep patterns were assessed after 1 and 3 months using the seven item Pittsburgh sleep quality index (PSQI), which measures subjective sleep quality, sleep latency, sleep duration, habitual sleep efficiency, sleep disturbances, use of sleeping medication, and daytime dysfunction; each item is scored from $0-3$ ( 0 indicates no difficulty, 3 indicates severe difficulty). ${ }^{32}$ 


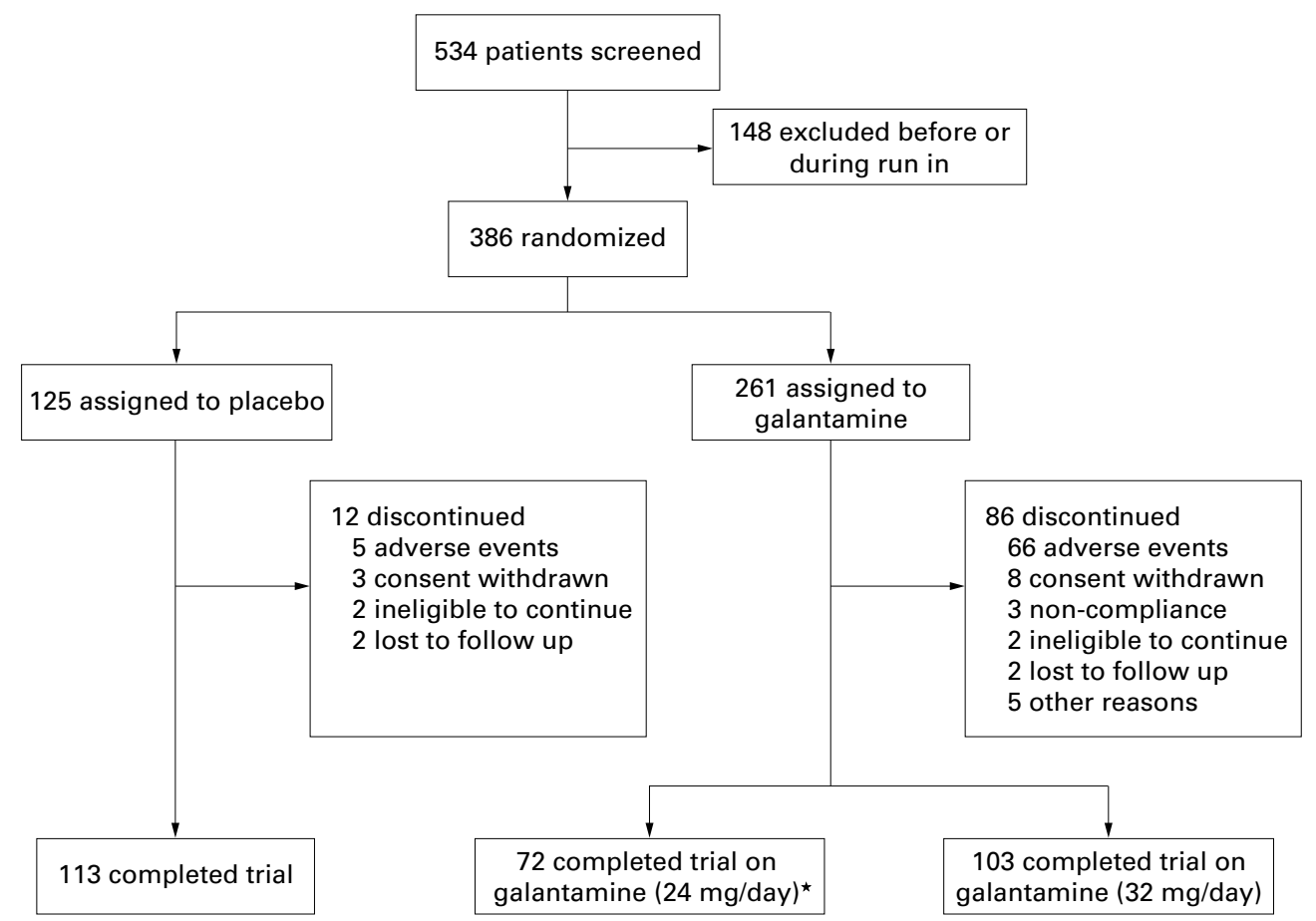

Figure 1 Trial profile.

\section{STATISTICAL ANALYSIS}

Using data from an earlier phase II trial, we calculated that 94 patients were needed to complete the study in the placebo group, and twice this number in the galantamine group, to achieve $80 \%$ power $(\alpha=0.05)$ for detecting a 2.5 point difference in the change in ADAS$\operatorname{cog} / 11$ score between patients treated with placebo and with each of the maximum daily doses of galantamine.

All randomised patients who took at least one dose of trial medication were included in the analyses of baseline characteristics and safety data. As we were chiefly concerned with assessing the treatment effects of the maximum daily doses of galantamine (24-32 mg/day), a traditional "observed cases" (OC) analysis at 3 months was the primary efficacy analysis; this included patients who provided postbaseline data for ADAS-cog/11, CIBIC-plus, or DAD variables at the designated assessment times. More conservative 3 month, intention to treat

Table 1 Baseline characteristics

\begin{tabular}{|c|c|c|}
\hline Characteristic & $\begin{array}{l}\text { Placebo } \\
(n=125)\end{array}$ & $\begin{array}{l}\text { Galantamine } \\
24-32 \mathrm{mg} \\
(n=261)\end{array}$ \\
\hline \multicolumn{3}{|l|}{ Demography: } \\
\hline Males/females & $58 / 67$ & $113 / 148$ \\
\hline $\operatorname{Age}(y)^{\star}$ & $74.6(0.68)$ & $75.2(0.45)$ \\
\hline \multicolumn{3}{|l|}{ Clinical: } \\
\hline Weight $(\mathrm{kg})^{\star}$ & $68.5(1.37)$ & $66.1(0.86)$ \\
\hline Smokers & $9(7.2)$ & $21(8.0)$ \\
\hline Other active medical conditions & $112(89.6)$ & $235(90.0)$ \\
\hline \multicolumn{3}{|l|}{ ApoE $\varepsilon 4$ genotype: } \\
\hline Homozygous & $14(13.0)$ & $38(16.7)$ \\
\hline Heterozygous & $56(51.8)$ & $111(48.9)$ \\
\hline Total MMSE score ${ }^{\star}$ & $19.6(0.32)$ & $19.7(0.24)$ \\
\hline ADAS- $\operatorname{cog} / 11$ score ${ }^{\star}$ & $24.7(0.85)$ & $25.6(0.65)$ \\
\hline Total NPI score ${ }^{\star}$ & $9.4(1.01)$ & $9.2(0.66)$ \\
\hline Total DAD score s $^{\star}$ & $73.0(1.91)$ & $69.1(1.42)$ \\
\hline Time since cognitive problem diagnosed $(y)^{\star}$ & $3.22(0.19)$ & $3.8(0.20)$ \\
\hline Time since probable Alzheimer's disease diagnosed $(\mathrm{y})^{\star}$ & $0.69(0.1)$ & $0.71(0.07)$ \\
\hline
\end{tabular}

Data are number (\%) of patients, except those marked * which denotes mean (SE).
(ITT) analyses were also performed to examine the robustness of the efficacy results. This included classic ITT analysis (according to assigned treatment and using the last observation available for each patient regardless of whether they took trial medication), and the traditional last observation carried forward (LOCF) analysis (using the last postbaseline observations available for each patient who received treatment). All results discussed are based on OC analysis unless otherwise stated.

Baseline characteristics of the three groups were compared using two way analyses of variance (ANOVA) for continuous variables and generalised Cochran-Mantel-Haenszel tests for categorical variables. Changes from baseline in efficacy variables, vital signs, and body weight were assessed using two tailed, paired $t$ tests. Comparisons of variables between the galantamine and placebo groups employed the following methods: ANOVA for changes from baseline in ADAS-cog subscales, DAD, PSQI, and vital signs; generalised Cochran-MantelHaenszel tests for ADAS-cog/11 response rates; and Van Elteren tests ${ }^{33}$ for CIBIC-plus. The critical level of significance was set as $\mathrm{p} \leqslant 0.05$. The statistical software used in these analyses was SAS version 6.12.

\section{Results}

Five hundred and thirty four patients were screened for the study and 386 were randomised to trial medication, of whom $75 \%$ completed the study (fig 1). During week 4, 64 patients remained on the $24 \mathrm{mg}$ /day dose of galantamine, whereas 165 were escalated to the $32 \mathrm{mg} /$ day dose, of whom 40 (24\%) reverted to the lower dose during that week. Of the 125 patients remaining on the higher dose by the end of week 4, 103 (82\%) completed the study. 
Table 2 Efficacy outcomes after 3 months

\begin{tabular}{|c|c|c|c|c|c|c|c|c|c|}
\hline \multirow[b]{2}{*}{ Assessment } & \multicolumn{3}{|l|}{ Placebo } & \multicolumn{6}{|c|}{ Galantamine 24-32 mg/day } \\
\hline & Classic ITT & $\operatorname{ITT}(L O C F)$ & $O C$ & \multicolumn{2}{|l|}{ Classical ITT } & \multicolumn{2}{|c|}{$I T T(L O C F)$} & \multicolumn{2}{|l|}{$O C$} \\
\hline $\begin{array}{l}\text { ADAS-cog/11 (mean (SE) change from } \\
\text { baseline) }\end{array}$ & $\begin{array}{l}+0.7(0.47) \\
(\mathrm{n}=125)\end{array}$ & $\begin{array}{l}+0.6(0.45) \\
(\mathrm{n}=120)\end{array}$ & $\begin{array}{l}+0.5(0.42) \\
(\mathrm{n}=108)\end{array}$ & \multicolumn{2}{|l|}{$\begin{array}{l}-0.9(0.31)^{\star \star} \\
(\mathrm{n}=260)\end{array}$} & \multicolumn{2}{|c|}{$\begin{array}{l}-1.1(0.33)^{\star \star} \\
(\mathrm{n}=239)\end{array}$} & \multicolumn{2}{|c|}{$\begin{array}{l}-1.4(0.4)^{\star \star} \\
(\mathrm{n}=170)\end{array}$} \\
\hline $\begin{array}{l}\text { ADAS-cog/13 (mean (SE) change from } \\
\text { baseline) }\end{array}$ & $\begin{array}{l}+0.7(0.52) \\
(\mathrm{n}=123)\end{array}$ & $\begin{array}{l}+0.7(0.51) \\
(\mathrm{n}=120)\end{array}$ & $\begin{array}{l}+0.5(0.49) \\
(\mathrm{n}=106)\end{array}$ & \multicolumn{2}{|l|}{$\begin{array}{l}-1.1(0.36)^{\star \star} \\
(\mathrm{n}=258)\end{array}$} & \multicolumn{2}{|c|}{$\begin{array}{l}-1.2(0.38)^{\star \star} \\
(\mathrm{n}=239)\end{array}$} & \multicolumn{2}{|c|}{$\begin{array}{l}-1.6(0.46)^{\star \star \star} \\
(\mathrm{n}=170)\end{array}$} \\
\hline No $(\%)$ ADAS-cog/ 11 responders & $(\mathrm{n}=123)$ & $(\mathrm{n}=120)$ & $(\mathrm{n}=100)$ & \multicolumn{2}{|l|}{$(\mathrm{n}=258)$} & \multicolumn{2}{|c|}{$(n=239)$} & \multicolumn{2}{|c|}{$(n=170)$} \\
\hline$\geqslant 4$ points improvement & $27(22.0)$ & $27(22.5)$ & $21(19.4)$ & \multirow{2}{*}{\multicolumn{2}{|c|}{$\begin{array}{l}73(28.3) \\
(\mathrm{n}=248)\end{array}$}} & \multirow{2}{*}{\multicolumn{2}{|c|}{$\begin{array}{l}72(30.1) \\
(\mathrm{n}=240)\end{array}$}} & \multirow{2}{*}{\multicolumn{2}{|c|}{$\begin{array}{l}56(32.9)^{\star} \\
(\mathrm{n}=170)\end{array}$}} \\
\hline CIBIC-Plus (No (\%) patients in each category) & $(\mathrm{n}=124)$ & $(\mathrm{n}=123)$ & $(\mathrm{n}=111)$ & & & & & & \\
\hline $1=$ Markedly improved & $0(0)$ & $0(0)$ & $0(0)$ & \multicolumn{2}{|l|}{$1(0.4)$} & \multicolumn{2}{|l|}{$1(0.4)$} & \multicolumn{2}{|l|}{$1(0.6)$} \\
\hline $2=$ Moderately improved & $1(0.8)$ & $1(0.8)$ & $1(0.9)$ & \multicolumn{2}{|l|}{$7(2.8)$} & \multicolumn{2}{|l|}{$7(2.9)$} & \multicolumn{2}{|l|}{$7(4.1)$} \\
\hline 3=Minimally improved & $23(18.5)$ & $23(18.7)$ & $21(18.9)$ & $56(22.6)$ & & \multicolumn{2}{|l|}{$53(22.1)$} & \multicolumn{2}{|l|}{$41(24.1)$} \\
\hline $4=$ No change & $54(43.5)$ & $53(43.1)$ & $48(43.2)$ & $132(53.2)$ & $\star \star$ & $133(55.4)$ & $\star \star$ & $86(50.6)$ & $\star \star$ \\
\hline $5=$ Minimally worsened & $36(29.0)$ & $36(29.3)$ & $31(27.9)$ & \multicolumn{2}{|l|}{$43(17.3)$} & \multicolumn{2}{|l|}{$40(16.7)$} & \multicolumn{2}{|l|}{$30(17.6)$} \\
\hline $6=$ Moderately worsened & $9(7.3)$ & $9(7.3)$ & $9(8.1)$ & \multicolumn{2}{|l|}{$8(3.2)$} & \multicolumn{2}{|l|}{$6(2.5)$} & \multicolumn{2}{|l|}{$5(2.9)$} \\
\hline $7=$ Markedly worsened & $1(0.8)$ & $1(0.8)$ & $1(0.9)$ & \multicolumn{2}{|l|}{$1(0.4)$} & \multicolumn{2}{|l|}{$0(0)$} & \multicolumn{2}{|l|}{$0(0.0)$} \\
\hline NPI (mean (SE) change from baseline) & $\begin{array}{l}+0.5(0.64) \\
(n=125)\end{array}$ & $\begin{array}{l}+0.5(0.65) \\
(\mathrm{n}=123)\end{array}$ & $\begin{array}{l}0.0(0.65) \\
(n=110)\end{array}$ & \multirow{2}{*}{\multicolumn{2}{|c|}{$\begin{array}{l}-0.4(0.65) \\
(\mathrm{n}=261) \\
-1.2(0.83)^{\star \star} \\
(\mathrm{n}=261)\end{array}$}} & $\begin{array}{l}-0.3(0.7) \\
(\mathrm{n}=241)\end{array}$ & & $\begin{array}{l}-0.7(0.77) \\
(\mathrm{n}=172)\end{array}$ & \\
\hline $\mathrm{DAD}$ (mean (SE) change from baseline) & $\begin{array}{l}-5.3(1.17) \\
(\mathrm{n}=125)\end{array}$ & $\begin{array}{l}-5.2(1.18) \\
(\mathrm{n}=123)\end{array}$ & $\begin{array}{l}-4.2(1.16) \\
(\mathrm{n}=110)\end{array}$ & & & $\begin{array}{l}-0.4(0.76) \\
(\mathrm{n}=241)\end{array}$ & & $\begin{array}{l}0.1(0.87)^{\star} \\
(\mathrm{n}=172)\end{array}$ & \\
\hline
\end{tabular}

${ }^{\star} \mathrm{p}<0.05 ;{ }^{\star \star} \mathrm{p}<0.01 ;{ }^{\star \star \star} \mathrm{p}<0.001 v$ placebo

ITT $=$ Intention to treat analysis; LOCF $=$ Last observation carried forward analysis; OC $=$ Observed cases analysis.

Of the patients who continued on, or reverted to, the lower dose during week 4, 72 (69\%) completed the study. The baseline characteristics of the treatment groups were comparable (table 1). The proportions of patients taking concomitant medication (most commonly analgaesics) during the double blind phase of the study were comparable between treatment groups ( $89 \%$, placebo and $88 \%$, galantamine). A slightly greater proportion of patients in the galantamine group (33\% (85/261)) compared with those receiving placebo (25\% (31/125)) took concomitant psychotropic medications.

Protocol deviations occurred in $38(10 \%)$ of randomised patients. Use of prohibited medications (20 cases) was the most common problem.

EFFICACY

Galantamine treated patients showed significantly superior cognitive function when compared with placebo treated patients, the mean treatment effect in favour of galantamine being 1.1 points $(\mathrm{p}<0.05)$ at 1 month and 1.9 points $(p=0.002)$ at 3 months on the ADAS-cog/11 subscale (fig 2). These treatment differences were due to ADAS-cog/11 scores significantly improving from baseline in galantamine treated patients at both time points $(\mathrm{p}<0.001$ in both cases), while not changing significantly in the placebo group (table 2). At 3 months, there was no difference in those who received $32 \mathrm{mg}$ /day or $24 \mathrm{mg} /$ day galantamine in improvement

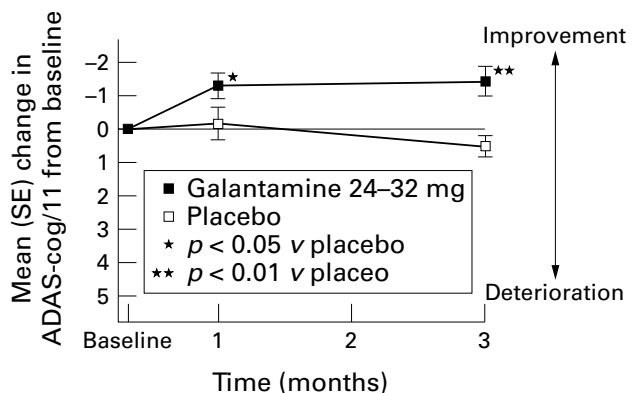

Figure 2 Mean change from baseline in ADAS-cog/11 scores over time. from baseline in ADAS-cog/11 during the fixed dose treatment period (mean (SE) 1.4 (0.57), $\mathrm{n}=99$, and 1.5 (0.54), $\mathrm{n}=71$, ADAS points respectively). All of these findings were confirmed by both ITT analyses. Galantamine also produced a significantly better outcome than placebo on the ADAS-cog/13 subscale $(\mathrm{p}=0.004)$ and ADAS-cog/11 responder rates $(\mathrm{p}=0.02$, table 2$)$.

The overall clinical response to galantamine at 3 months, as measured by CIBIC-plus, was significantly better than with placebo ( $p=0.003$; significance confirmed by both ITT analyses, table 2 ). Only $21 \%$ of patients on galantamine $(n=170)$ deteriorated compared with $37 \%(n=111)$ of those in the placebo group. Furthermore, galantamine produced significant benefits on activities of daily living as indicated by a drug-placebo difference in the mean change from baseline of 4.3 points in the total DAD score $(\mathrm{p}=0.004$; significance confirmed by both ITT analyses, table 2 , fig 3 ). Functional performance was preserved in galantamine treated patients, as indicated by a DAD score that was not significantly different from baseline. This preservation of functional activity was seen regardless of whether patients completed the study on a dose of $32 \mathrm{mg} /$ day or $24 \mathrm{mg} /$ day (mean (SE) changes of 0.6 (1.21), $\mathrm{n}=99$, and -0.5 (1.24), $\mathrm{n}=73$, respectively). By contrast, the decline in total DAD score for the placebo group was statistically significant $(\mathrm{p}<0.001$ for OC and ITT analyses). At 3

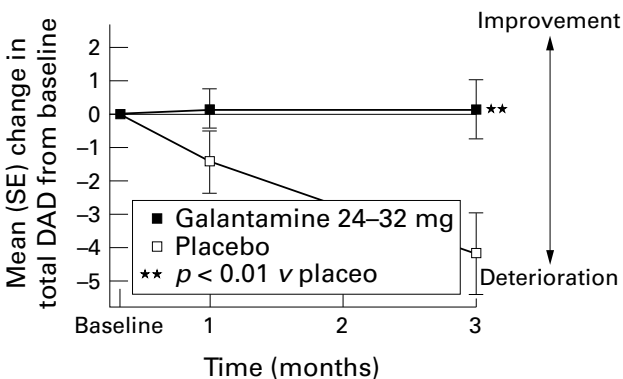

Figure 3 Mean change from baseline in total DAD scores over time. 


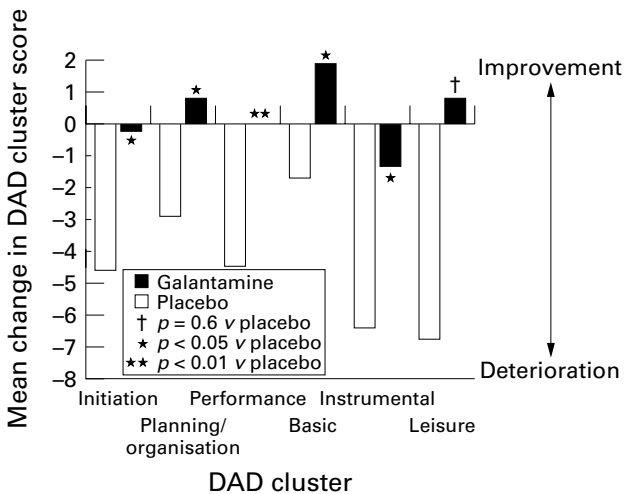

Figure 4 Mean change from baseline in DAD cluster scores at 3 months.

Table 3 Number (\%) patients with adverse events occurring at least 5\% more often with galantamine than with placebo

\begin{tabular}{lll}
\hline Adverse event & $\begin{array}{l}\text { Placebo } \\
(n=125)\end{array}$ & $\begin{array}{l}\text { Galantamine } \\
(n=261)\end{array}$ \\
\hline Nausea & $14(11.2)$ & $84(32.2)$ \\
Dizziness & $5(4.0)$ & $39(14.9)$ \\
Vomiting & $5(4.0)$ & $38(14.6)$ \\
Anorexia & $3(2.4)$ & $31(11.9)$ \\
Somnolence & $1(0.8)$ & $20(7.7)$ \\
Abdominal pain & $2(1.6)$ & $18(6.9)$ \\
Agitation & $1(0.8)$ & $16(6.1)$ \\
Any adverse event & $79(63.2)$ & $225(86.2)$ \\
\hline
\end{tabular}

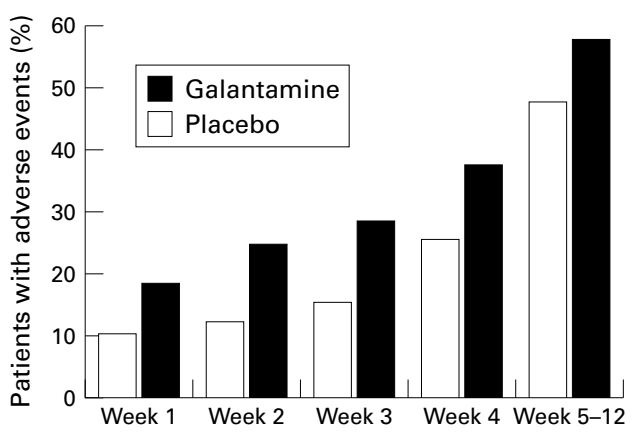

Figure 5 Incidence of adverse events by phase of study.

months, significant differences between the galantamine and placebo groups were also seen for each DAD cluster (fig 4): initiation, planning, performance as well as both basic and instrumental activities of daily living ( $p \leqslant 0.05$ for all OC and LOCF-ITT analyses), except for DAD-leisure ( $\mathrm{p}=0.06$ in OC analysis). At 3 months, the mean NPI scores had not significantly changed from baseline for both the galantamine and placebo groups (table 2).

SAFETY

Galantamine was well tolerated. Adverse events occurring at least $5 \%$ more often in either galantamine group than the placebo group are listed in table 3 . The incidence of adverse events during the dose escalation phase of the study in the galantamine group was greater than that in the placebo group. The difference between the placebo and galantamine groups in the frequency of adverse events was reduced during the maintenance phase (fig 5).

Most adverse events were mild to moderate in severity in both treatment groups, and the proportion of serious adverse events was comparable (6\% with placebo, $8 \%$ with galantamine). There were two deaths during the study, both in the placebo group. Discontinuations due to adverse events were more common in galantamine treated patients than in those receiving placebo (fig 1 ). The events most commonly associated with the discontinuations during galantamine therapy were nausea $(13 \%(33 / 261))$, vomiting (6\% (15/261)), dizziness $(5 \%(13 / 261))$, and anorexia $(4 \%$ $(11 / 261))$. There was only one report of muscle weakness-in a galantamine treated patientwhich was judged as probably unrelated to treatment.

Total PSQI scores did not change significantly in either treatment group during the study (a mean decrease of only 0.2 points in each case). There were no consistent trends or clinically important differences between treatment groups in blood chemistry, haematology, urinalysis, pulse rate, blood pressure, or ECG measurements during the study.

\section{Discussion}

This study showed that patients with mild to moderate Alzheimer's disease receiving galantamine experienced statistically significant benefits in cognition and global function after 4 and 12 weeks treatment. The clinical relevance of these findings was emphasised by the improvements seen in both the ADL measure and CIBIC-plus in the galantamine group on both observed case and ITT analyses. No benefit was found on behaviour, likely owing to the short duration of the trial and the exclusion of patients with behavioural problems at baseline. Although it is not possible to draw direct comparisons with another trial, the duration of the study may be important as in a similar, but longer, 5 month study the placebo group showed a significant increase in behavioural symptoms, whereas the galantamine group remained stable. ${ }^{34}$

Although the study conforms to the usual requirements for valid studies, ${ }^{35}{ }^{36}$ in our view, the short duration was the study's main limitation. However, the duration of galantamine treatment was long enough to demonstrate a therapeutic effect, even with a fairly rapid dose escalation, and to test our primary hypothesis about the effects of flexible dosing on tolerability. We used the OC analysis at 3 months as the primary analysis so that we could capture the effect of treatment on completers who had been maintained on 24 or $32 \mathrm{mg} /$ day galantamine, thus reflecting experience in clinical practice in patients who comply with treatment recommendations. Although the $\mathrm{OC}$ analysis may bias the results towards a larger treatment effect, especially as the drop out rate was higher in the galantamine group than in the placebo group, our findings are confirmed by more conservative ITT analyses.

Hitherto the lack of impact of cholinesterase inhibitors on function has been used to undermine the clinical importance of their cognitive effects, ${ }^{13} 14$ especially given the contribution of functional decline to caregiver burden and the cost of care. ${ }^{123738}$ The general consensus view 
is changing as functional improvement has been reported in other studies of galantamine $e^{39}$ and, at least for instrumental ADL, with donepezil. ${ }^{9}$ Whether the preservation of basic ADL seen in this study constitutes an advantage of galantamine over other treatments cannot be established without direct comparative studies, but evidence now exists that functional benefit can be demonstrated with cholinesterase inhibition.

The adverse events associated with galantamine in this study were generally those expected from cholinergic stimulation, and similar to those reported with other cholinesterase inhibitors. ${ }^{69-46}$ The adverse events were of mild to moderate severity, occurred primarily during the dose escalation phase and may be reduced further by using a slower dose escalation. ${ }^{34}$ In the present study, there was no evidence of hepatotoxicity, muscle weakness, or sleep disturbance, as has been reported for other cholinergic treatments. ${ }^{5-10}$

Of the patients escalated to the higher dose of galantamine during week 4 , most $(76 \%)$ remained on this dose during that week, and most of these $(82 \%)$ completed the study. Although flexible dose escalation seemed to allow investigators to select patients who would tolerate the higher dose, patients on $32 \mathrm{mg} /$ day did not seem to gain additional cognitive benefit over those who received $24 \mathrm{mg} /$ day (mean ADAS-cog improvement over baseline 1.4 and 1.5 points respectively). This is consistent with a 6 month placebo controlled study that did not show any clinically or statistically significant differences on primary efficacy variables between the 24 and $32 \mathrm{mg} /$ day doses of galantamine. ${ }^{23}$

This randomised, placebo controlled trial shows that galantamine produces cognitive and functional benefit in patients with mild to moderate Alzheimer's disease. Galantamine was well tolerated with no evidence of hepatotoxicity, muscle weakness, or sleep disturbance. These results suggest that galantamine will have a useful role in the treatment of Alzheimer's disease.

Clinical investigators: Australia, Boundy K, Clarnette R; Canada, Ancill R, Arts R, Black S, McCracken P, Merskey H, Molloy D, Rockwood K, Wherrett J; New Zealand, Davison G, Gilchrist N; South Africa, Browne G, Fritz V, Holmes R, Louw S, Laban P, Page M, Pretorius J; United Kingdom, Bonthala C, Ghosh M, Mahmood A, McMillan H, Pathy M, Bapuji Rao V, Rossiter J, Tym E, Williams A; United States, Aronson S, Blanchette P, De Priest M, Eisner L, Forred W, Frey J, Green R, Landbloom R, Mintzer J, Nakra R, Pahl J, Pendlebury W, Rymer $\mathrm{M}$, Shua-Haim J, Solomon P, Thein S, Thein S Jr, Tomlinson J. This study was supported by funding from Janssen Research Foundation, Beerse, Belgium. We are grateful to Max Lagnado of Oxford Clinical Communications who wrote an initial draft based on Clinical Trial Report N133910, which was prepared by Rolando Gutierrez of Janssen Research Foundation. We have reviewed the clinical trial report and related analyses, and are guarantors for the results presented. This report includes data guarantors for the results presented. This report includes data
generated by protocol GAL-INT-2, sponsored by Janssen generated by protocol GAL-INT-2, sponsored by Janssen
Research Foundation. KR has received honoraria for lectures, and three grants for clinical studies. JM has received compensation from Janssen for lectures, consulting and grants/studies. tion from Janssen for lectures, consulting and grants/studies. DW has received honoraria for conference presentations and for
consulting activities. KR, JM and DW do not own any stock or consulting activities. KR, JM and DW do not own any stock or
options in Janssen Pharmaceutica. TW and LT are employees of options in Janssen Pharmaceutica.
Janssen Research Foundation.

1 Bartus RT, Dean RL, Beer B, et al. The cholinergic hypothesis of geriatric memory dysfunction. Science. 1982;217:408-17.

2 Francis PT, Palmer AM, Snape M, et al. The cholinergic hypothesis of Alzheimer's disease: a review of progress. $\mathcal{F}$ Neurol Neurosurg Psychiatry 1999;66:137-47.

3 Schneider LS. New therapeutic approaches to Alzheimer's disease. F Clin Psychiatry 1996;57 (suppl 14):30-6. 4 Nordberg A, Svensson AL. Cholinesterase inhibitors in the treatment of Alzheimer's disease: a comparison of to

5 Watkins RB, Zimmerman HJ, Knapp MJ, et al. Hepatotoxic effects of tacrine administration in patients with Alzheimer's disease. FAMA 1994;271:992-8.

6 Antuono PG. Effectiveness and safety of velnacrine for the treatment of Alzheimer's disease. A double-blind, placebocontrolled study. Mentane Study Group. Arch Intern Med 1995;155:1766-72.

7 Thal LJ, Schwartz G, Sano M, et al. A multicenter doubleblind study of controlled-release physostigmine for the treatment of symptoms secondary to Alzheimer's disease.
Physostigmine Study Group. Neurology 1996;47:1389-95.

8 Rogers SL, Doody RS, Mohs RC, et al. Donepezil improves cognition and global function in Alzheimer's disease: a 15-week, double-blind, placebo-controlled study. Arch 15-week, double-blind, place
Intern Med 1998;158:1021-31.

9 Burns A, Rossor M, Hecker J, et al, and the international Donepezil Study Group. The effects of donepezil in Alzheimer's disease: results from a multinational trial. Dement Geriatr Cogn Disord 1999;10:237-44.

10 Anon. Bayer suspends metrifonate trials. Scrip 1998;2374: 9.

11 Riter RN, Fries BE. Predictors of the placement of cognitively impaired residents on special care units. Gerontologist 1992;32:184-90.

12 The Canadian Study of Health and Aging. Patterns of caring for people with dementia in Canada. Can F Aging 1994; 13:470-87.

13 Pryse-Phillips W. Do we have drugs for dementia? No. Arch Neurol 1999;56:735-7.

14 Bentham P, Gray R, Sellwood E, et al. Effectiveness of rivastigmine in Alzheimer's disease. Improvements in functional ability remain unestablished [letter]. BMF 1999;319: $640-1$.

15 Albuquerque EX, Alkondon M, Pereira EFR, et al. Properties of neuronal nicotinic acetylcholine receptors: pharmacological characterization and modulation of synaptic function. F Pharmacol Exp Ther 1997;280:1117-36.

16 Schrattenholz A, Pereira EFR, Roth U, et al. Agonist responses of neuronal nicotinic acetylcholine receptors are potentiated by a novel class of allosterically acting ligands. Mol Pharmacol 1996;49:1-6.

17 Vasilenko ET, Tonkopii VD. Characteristics of galanthamine as a reversible inhibitor of cholinesterase $\mathrm{Bi}$ okhimiia 1974;39:701-3. (In Russian.)

18 Bores GM, Huger FP, Petko W, et al. Pharmacological evaluation of novel Alzheimer's disease therapeutics: acetylcholinesterase inhibitors related to galanthamine. $\mathcal{f}$ Pharmacol Exp Ther 1996;277:728-38.

19 Whitehouse PJ, Martino AM, Antuono PG, et al. Nicotinic acetylcholine binding sites in Alzheimer's disease. Brain Res 1986;371:146-51.

20 Nordberg A, Nilsson-Hakansson L, Adem A, et al. The role of nicotinic receptors in the pathophysiology of Alzheimer's disease. Prog Brain Res 1989;79:353-62.

21 Newhouse PA, Potter A, Levin ED. Nicotinic system involvement in Alzheimer's and Parkinson's diseases. Implications for therapeutics. Drugs Aging 1997;11:206-28.

22 Levin ED, Simon BB. Nicotinic acetylcholine involvement in cognitive function in animals. Psychopharmacology (Berl) 1998;138:217-30.

23 Raskind MA, Peskind ER, Wessel T, et al. Galantamine in $\mathrm{AD}$ - A 6-month randomized, placebo-controlled trial with a 6-month extension. Neurology 2000;54:2261-8.

24 McKhann G, Drachman D, Folstein M, et al. Clinical diagnosis of Alzheimer's disease; report of the NINCDSADRDA Work Group under the auspices of Department of Health and Human Services Task Force on Alzheimer's Disease. Neurology 1984;34:939-44.

25 Folstein MF, Folstein SE, McHugh PR. Mini-mental state. A practical method for grading the cognitive state of patients for the clinician. F Psychiatr Res 1975;12:189-98.

26 Rosen WG, Mohs RC, Davis KL. A new rating scale for Alzheimer's disease. Am f Psychiatry 1984;141:1356-64.

27 Schneider LS, Olin JT, Doody RS, et al. Validity and reliability of the Alzheimer's disease cooperative study: clinical global impression of change. The Alzheimer's disease cooperative study. Alzheimer Dis Assoc Disord 1997; 11 (suppl 2):S22-32

28 Mohs RC, Knopman D, Petersen RC, et al. Development of cognitive instruments for use in clinical trials of antidementia drugs: additions to the Alzheimer's disease assessment scale that broadens its scope. The Alzheimer's Disease cooperative study. Alzheimer Dis Assoc Disord 1997; 11(suppl 2):S13-21.

29 Peripheral and Central Nervous System Drugs Advisory Committee Meeting, Fuly 7, 1989. Rockville, MD: Department of Health and Human Services, Public Heath Service, Food and Drug Administration, 1989:227

30 Cummings JL, Mega M, Gray K, et al. The neuropsychiatric inventory: comprehensive assessment of psychopathology in dementia. Neurology 1994;44:2308-14.

31 Gelinas I, Gauthier L, McIntyre M, et al. Development of a functional measure for persons with Alzheimer's disease: the disability assessment for dementia. Am $\mathcal{F}$ Occup Ther 1999;53:471-81.

32 Buysse DJ, Reynolds CF, Monk TH, et al. The Pittsburgh sleep quality index: a new instrument for psychiatry practice and research. Psychiatry Res 1989;28:193-213.

33 Van Elteren PH. On the combination of independent two sample tests of Wilcoxon. Bulletins of the Institute of Internal Statististics 1960;37:351-61. 
34 Tariot P, Solomon P, Morris J, et al. A 5 month, randomized, placebo-controlled study of galantamine in AD. Neurology 2000;54:2269-76.

35 Rockwood K, MacKnight C. Assessing the clinical importance of statistically significant improvement in antidementia drug trials. Neuroepidemiology 2001;20:51-6.

36 Begg C, Cho M, Eastwood S, et al. Improving the quality of reporting of randomized controlled trials. $\mathcal{F A M A} 1996 ; 276$ 637-639

37 Wolinsky FD, Callahan CM, Fitzgerald JF, et al. Changes in functional status and the risks of subsequent nursing home placement and death. F Gerontol 1993;48:S94-101.

38 Glazebrook K, Rockwood K. Case control study of the risks for institutionalization of elderly people in Nova Scotia. Can F Aging. 1994;13:104-17.

39 Wilcock GK, Parys W, Lilienfeld S, et al. Efficacy and safety of galantamine in patients with mild to moderate Alzheimer's disease: a multicentre randomised controlled Alzheimer's disease: a multic

40 Raskind MA, Cyrus PA, Ruzicka BB, et al. The effects of metrifonate on the cognitive, behavioral, and functional metrifonate on the cognitive, behavioral, and functional
performance of Alzheimer's disease patients. F Clin

41 Corey-Bloom J, Anand R, Veach J, et al. A randomized trial evaluating the efficacy and safety of ENA 713 (rivastigmine tartrate), a new acetylcholinesterase inhibitor, in patients with mild to moderately severe Alzheimer's disease. International fournal of Geriatric Psychopharmacology 1998; 1:55-65.
42 Rösler M, Anand R, Cicin-Sain A, et al. Efficacy and safety of rivastigmine in patients with Alzheimer's disease: international randomised controlled trial. BMF 1999;318: 633-8.

43 Knapp MJ, Knopman DS, Solomon PR, et al. A 30 week randomized controlled trial of high dose tacrine in patients with Alzheimer's disease. $7 A M A$ 1994;271:985-91.

44 Rogers SL, Farlow MR, Doody RS, et al. A 24 week, double-blind, placebo-controlled trial of donepezil in patients with Alzheimer's disease. Neurology 1998;50:13645.

45 Farlow MR, Evans RM. Pharmacological treatment of cognition in Alzheimer's dementia. Neurology 1998;51(suppl 1):S36-44; discussion S65-67.

46 Morris JC, Cyrus PA, Orazem J, et al. Metrifonate benefits cognitive, behavioral, and global function in patients with Alzheimer's disease. Neurology 1998;50:1222-30.

47 Barclay LL, Zemcov A, Blass JP, et al. Survival in Alzheimer's disease and vascular dementias. Neurology 1985;35:834-40.

48 Rockwood K, Stolee P, Howard K, et al. Use of goal attainment scaling to measure treatment effects in an antidementia drug trial. Neuroepidemiology 1996;15:330-8.

49 Rogers SL, Friedhoff LT, the Donepezil Study Group. The efficacy and safety of donepezil in patients with Alzheimer's disease: results of a US multicentre, randomized, doubleblind, placebo-controlled trial. Dementia 1996;7:293-303.

\section{Browsing made easy}

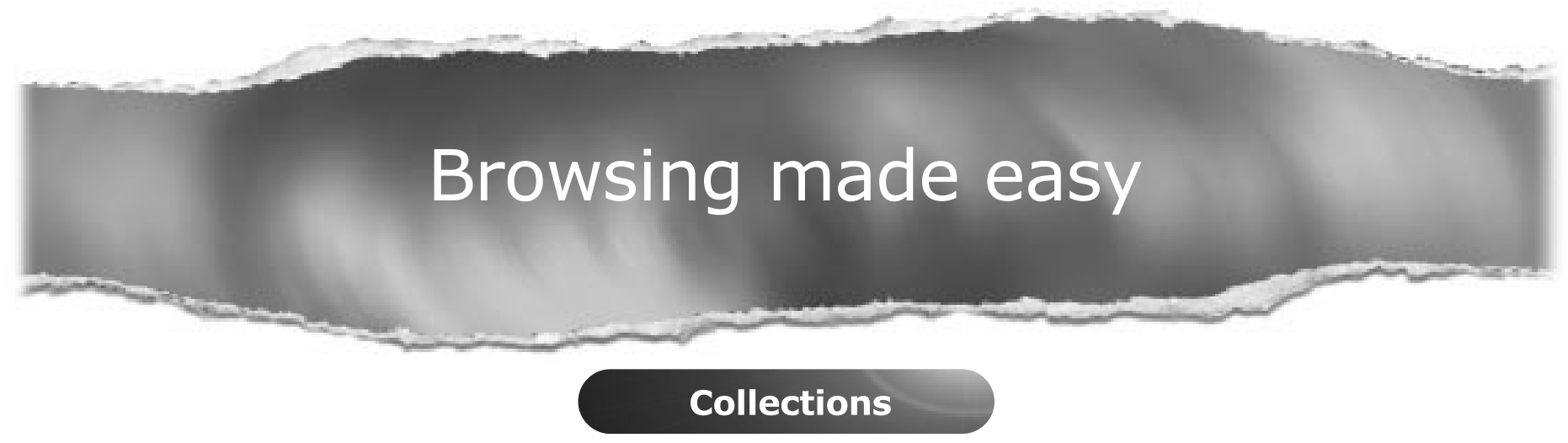

With a single click Collections allows you to find all articles that have been published in your chosen subject. Select from over 200 clinical and non-clinical topic collections and/or cross search other specialist journals, the BMJ and Cochrane Reviews

www.jnnp.com 